\title{
ANALYSIS OF SEMEN STUDIES OF 200 MEN ATTENDING AN INFERTILITY CLINIC IN A TERTIARY CARE CENTRE
}

\author{
Vinayachandran Sathyavrathan', Sajala Vimalraj ${ }^{2}$, Priya Narayanan 3 , Sarah Naushad ${ }^{4}$ \\ 1 Professor, Department of Obstetrics and Gynaecology, GMC, Kozhikode. \\ ${ }^{2}$ Additional Professor, Department of Obstetrics and Gynaecology, GMC, Kozhikode. \\ ${ }^{3}$ Associate Professor, Department of Obstetrics and Gynaecology, GMC, Kozhikode. \\ ${ }_{4}^{4}$ Senior Resident, Department of Obstetrics and Gynaecology, GMC, Kozhikode.
}

\section{BACKGROUND}

ABSTRACT

Various characteristics of the male population reporting for infertility evaluation were seen in their semen studies.

Aim- To study the various variables of the semen analysis data.

\section{MATERIALS AND METHODS}

Prospective observational study (May-September 2016).

Analysis- SPSS v16.

\section{RESULTS}

200 semen analyses were done in the study period; <30 years- $8.5 \%, 30-35$ years- $40 \%$, 36-40 years- $25 \%$, $40-45$ years- $19.5 \%$, $>45$ years $-7 \%$. The various semen analysis results were as follows: Mild asthenozoospermia- $65 \%$, mild asthenoteratozoospermia$3 \%$, mild oligoasthenozoospermia- $13 \%$, severe oligoasthenozoospermia- $16 \%$, azoospermia- 0.001\%, normozoospermia- 3\%. The severe oligoasthenozoospermic patients were more in the 30-35 age groups (14 patients). The mean and standard deviation for the analysed patients in the following parameters is as mentioned, total count- 57.87 million \pm 11 million, total motility- $55 \% \pm$ $17 \%$. Progressive motility- $14 \% \pm 6 \%$, Morphology normal forms- $1.8 \% \pm 0.8 \%$, Abnormal morphology distribution were mainly contributed by head defects- $89 \%$, followed by mid pieces (6\%), tail (4\%) and cytoplasmic droplets (1\%). Abstinence $>4$ days was noted to be associated with progressive motility $<25(<0.05)$.

\section{CONCLUSION}

Male factor contributes to almost 30\% - 40\% of reproductive failure, with teratozoospermia being very commonly seen. A detailed risk factor analysis will help in identifying any modifiable factors.

\section{KEYWORDS}

Semen Analysis Parameters, Male, Infertility.

HOW TO CITE THIS ARTICLE: Sathyavrathan V, Vimalraj S, Narayanan P, et al. Analysis of semen studies of 200 men attending an infertility clinic in a tertiary care centre. J. Evolution Med. Dent. Sci. 2017;6(93):6680-6682, DOI: 10.14260/jemds/2017/1447

\section{BACKGROUND}

According to International Committee for Monitoring Assisted Reproductive Technology and World Health Organization, 'Infertility' is a disease of reproductive system defined by failure to achieve clinical pregnancy after 12 months or more of regular unprotected sexual intercourse with same partner.(1)

Even though the recent growth of the Indian population has been unprecedented, there are substantial numbers of infertile couples in India that have an equally great concern.(2) Male reproductive function in the general population has gained more attention due to the occurrence of several biological problems affecting the male genital tract and has increased during the last 50 years. Abnormalities in the male partners are the sole cause of infertility in almost $20 \%$ of

'Financial or Other Competing Interest': None.

Submission 25-10-2017, Peer Review 22-11-2017,

Acceptance 27-11-2017, Published 11-12-2017.

Corresponding Author:

Dr. Sajala Vimalraj,

\#29/2298 Swapna

P.O Kuthiravattam,

Calicut -16.

E-mail: sajalavimalraj@gmail.com

DOI: $10.14260 /$ jemds $/ 2017 / 1447$ infertile couples and are important contributing factors in another $20 \%(40 \%)$ of couples with reproductive failure. In around $1-10 \%$ of cases, the cause is often treatable.(3) Hence, while investigating infertile couples, it is advisable that evaluation of male and female partners occur in parallel. $(4,5)$

Infertility is an equally important national problem concerning reproductive health and the infertile couples should be treated by assisted reproductive technology (ART) for procreation.(2) According to a study by WHO, the incidence of infertility in India is not yet clear. It is estimated that approximately 13 to 19 million couples are infertile.(6) The overall prevalence of primary infertility ranges between $3.9 \%$ and $16.8 \%$. Also the estimates of infertility vary widely among Indian states from 3.7\% in Uttar Pradesh, Himachal Pradesh and Maharashtra, to 5\% in Andhra Pradesh, and $15 \%$ in Kashmir.(7)

Although not a true measure of fertility, semen analysis is the cornerstone of evaluation of the male partner and should be one of the first investigations in any couple under evaluation for infertility. If abnormal, it suggests that the probability of achieving fertility is lower than normal.(8) Semen analysis remains the single most useful and fundamental investigation with a sensitivity of $89.6 \%$.(9) 
The aetiology of the male infertility is multifactorial and little is known about the causative factors leading to decrease in spermatogenesis. In men, the main causes of infertility are oligozoospermia, asthenozoospermia, teratozoospermia and azoospermia, which account for $20-25 \%$ of cases.(10,11) It is therefore important to understand the various abnormalities that occur in the semen parameters. Hence, this study was conducted to analyse the various characteristics of the male population reporting for infertility evaluation with respect to their semen parameters.

\section{Aim}

To study the various variables of the semen analysis data.

\section{MATERIALS AND METHODS}

This study was conducted as a prospective observational study from May to September 2016, at the Fertility Centre in IMCH, Govt. Medical College, Kozhikode, a tertiary care hospital in northern Kerala. All couples registering at the centre were subjected to a Semen analysis, from the department. 180 semen analyses were done in the period from May to September 2016, using the WHO 2010 reference ranges.(4) Data was analysed using the SPSS v 16 software.

\section{RESULTS}

180 men who had attended our infertility clinic were subjected to semen analysis. The age distribution of the study group included $8.5 \%$ in $<30,40 \%$ in $30-35,25 \%$ in $36-40$ years, $19.5 \%$ in $40-45$ years and $7 \%$ in $>45$ years. Almost $65 \%$ men are in the $30-40$ years age group, showing the average age at marriage and accessing treatment for infertility.

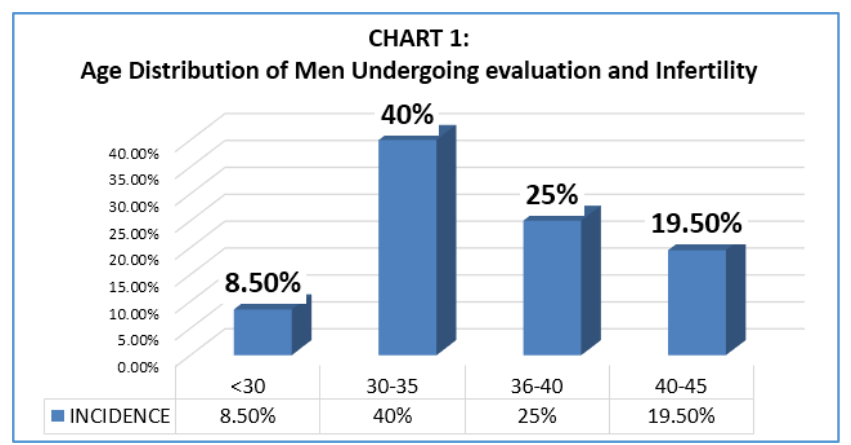

The semen analysis reports were as per WHO 2010 guidelines. Our institutional incidence of mild asthenoteratozoospermia was $65 \%$, mild oligoasthenozoospermia was 13\%, severe oligoasthenozoospermia was $16 \%$, mild asthenozoospermia was $3 \%$ and azoospermia was $0.001 \%$ and normozoospermia was $3 \%$. Thus, a normal semen analysis was seen in only $3 \%$ of men attending the clinic, while $16 \%$ showed severe anomalies of count, motility and morphology. The rest of the $84 \%$ men had mild abnormalities of count, motility and/or morphology.

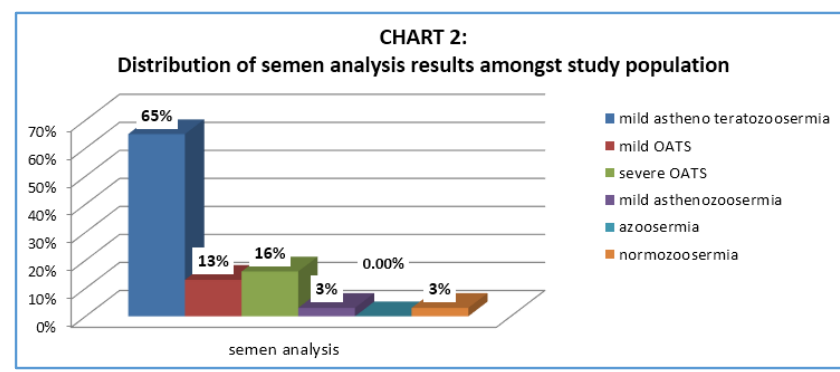

The morphological defects were as follows: Head defects were the commonest at $89 \%$, mid piece defects were seen in $6 \%$, tail defects were seen in $4 \%$ and cytoplasmic defects in $1 \%$.
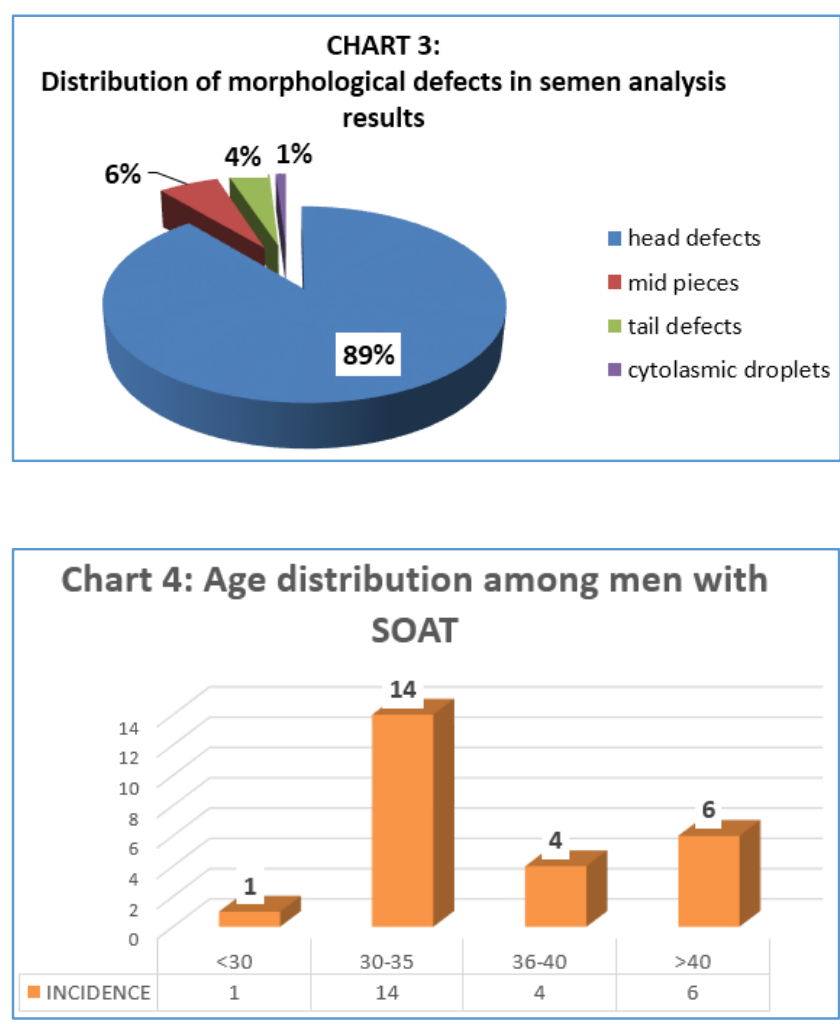

Of the 25 men who had severe oligoasthenoteratozoospermia, $14(56 \%)$ were in the $30-35$ years age group and $10(40 \%)$ were above 35 years of age.

\section{DISCUSSION}

180 semen analyses were done in the study period. Almost $65 \%$ men were in the $30-40$ years age group, showing the average age at marriage and accessing treatment for infertility. The results did not show that increasing age was a significant factor in abnormal semen parameters. In the study by Nadia AS et al, they however, noted a direct correlation between increasing age and abnormal semen analysis/infertility.(12) Hossain M et al \& Silvia et al stated that with an increasing trend of elderly men seeking fertility treatment, semen analysis parameters were found to be significantly abnormal. $(13,14)$ 
A normal semen analysis was seen in only $3 \%$ of men attending the clinic, while $16 \%$ showed severe anomalies of count, motility and morphology. The rest of the $84 \%$ men had mild abnormalities of count, motility and/or morphology. Male factor is thought to cause about $40 \%$ of infertility and also present in about $20 \%$ of cases with a combined factor. But probably, there were more cases of male factor in our study due to the higher costs involved in treating male factor in the private setup. The severe oligoasthenozoospermic patients were more in the 30-35 age groups (14 patients).(15)

In the study by Kumar et al on the evaluation of infertile men in rural India, their trend of semen analysis was as follows: $35.80 \%$ had normozoospermia, $34.14 \%$ had oligozoospermia, $19.35 \%$ had asthenoteratozoospermia and $10.70 \%$ had azoospermia.(16) This could point to stark difference in the lifestyle in Rural vs. urban setup affecting an individual's reproductive capabilities.(16)

The mean and standard deviation for the analysed patients in the following parameters is as mentioned-

- Total count -57.87 million \pm 11 million.

- Total motility- $55 \% \pm 17 \%$.

- Progressive motility $-14 \% \pm 6 \%$.

- Morphology normal forms- $1.8 \% \pm 0.8 \%$.

Abnormal morphology distribution was mainly contributed by head defects $89 \%$, followed by mid pieces $(6 \%)$, tail $(4 \%)$ and cytoplasmic droplets (1\%).

Abstinence $>4$ days was noted to be associated with progressive motility of $<25(<0.05)$. This was also echoed in studies by Al-Turki et al. (17)

Standard semen analysis has long been the primary laboratory test to find out male fecundity. Male sterility still poses a diagnostic problem and remains difficult to treat. Subfertility is the another condition which is characterised by sperm concentration less than $15 \times 10 \% / \mathrm{mL}$, less than $32 \%$ showing forward progression motility, and normal morphology in less than $4 \%{ }^{(8)}$

\section{CONCLUSION}

Male factor contributes to almost $30-40 \%$ of reproductive failure, with teratozoospermia being very commonly seen. A detailed risk factor analysis will help in identifying any modifiable factors.

\section{ACKNOWLEDGEMENT}

Professor Dr Sumangala Devi, Head of Department, OB-GYN; Dr. Ajitha B. K., Assistant Professor, Statistics Department, OB-GYN; Ms Sudha, Embryologist.

\section{REFERENCES}

[1] Zegers-Hochschild F, Adamson GD, de Mouzon J, et al. International Committee for Monitoring Assisted Reproductive Technology (ICMART) and the World Health Organization (WHO) revised glossary of ART terminology, 2009. Fertil Steril 2009;92(5):1520-4.

[2] Seshagiri PB. Molecular insights into the causes of male infertility. J Biosci 2001;26(Suppl 4):429-35.
[3] Fritz MA, Speroff L. Clinical gynecologic endocrinology and infertility. $8^{\text {th }}$ edn. Philadelphia: Wolters Kluwer Health/Lippincott Williams \& Wilkins 2011.

[4] Practice Committee of the American Society for Reproductive Medicine. Diagnostic evaluation of the infertile male: a committee opinion. Fertil Steril 2015;103(3):e18-e25.

[5] Toppari J, Larsen JC, Christiansen P, et al. Male reproductive health and environmental xenoestrogens. Environ Health Perspect 1996;104(Suppl 4):741-803.

[6] Bhaduri N(Bhattacharyya), Sarkar AP, Dewasi N, et al. Abnormalities in semen analysis among male partners of infertile couples: a study in a tertiary care level hospital of West Bengal, India. Int J Reprod Contracept Obstet \& Gynecol 2015;4(1):100-2.

[7] Zargar AH, Wani AI, Masoodi SR, et al. Epidemiologic and etiologic aspects of primary infertility in the Kashmir region of India. Fertil Steril 1997;68(4):63743.

[8] World Health Organization. WHO laboratory manual for the examination and processing of human semen. $5^{\text {th }}$ edn. Geneva: World Health Organization 2010.

[9] Barraud-Lange V, Sifer C, Pocaté K, et al. Short gamete co-incubation during in vitro fertilization decreases the fertilization rate and does not improve embryo quality: a prospective auto controlled study. J Assist Reprod Genet 2008;25(7):305-10.

[10] Cocuzza M, Alvarenga C, Pagani R. The epidemiology and etiology of azoospermia. Clinics (Sao Paulo) 2013;68(Suppl 1):15-26.

[11] Kumar N, Singh AK. Trends of male factor infertility, an important cause of infertility: a review of literature. J Hum Reprod Sci 2015;8(4):191-6.

[12] Aleisa NAS. Semen characteristics of fertile and subfertile men in a fertility clinic and correlation with age. Journal of King Saud University - Science 2013;25(1):63-71.

[13] Silva LF, Oliveira JB, Petersen CG, et al. The effects of male age on sperm analysis by motile sperm organelle morphology examination (MSOME). Reprod Biol Endocrinol 2012;10:19.

[14] Hossain MM, Fatima P, Rahman D, et al. Semen parameters at different age groups of male partners of infertile couples. Mymensingh Med J 2012;21(2):30615.

[15] Jajoo S, Kalyani KR. Prevalence of abnormal semen analysis in patients of infertility at a rural setup in Central India. Int J Reprod Contracept Obstet Gynecol 2013;2(2):161-4.

[16] Kumar R. Male infertility - current concepts. Indian J Urol 2011;27(1):39-40.

[17] Al-Turki HA. A 5-year analysis of semen parameters in Saudi Arabian men attending infertility clinics. J Int Med Res 2016;44(3):656-61. 